\title{
Uorden
}

\section{Paths to a sustainable agricultural system}

Pathways to a Nordic agricultural and food system with reduced emissions of greenhouse gases and air pollutants
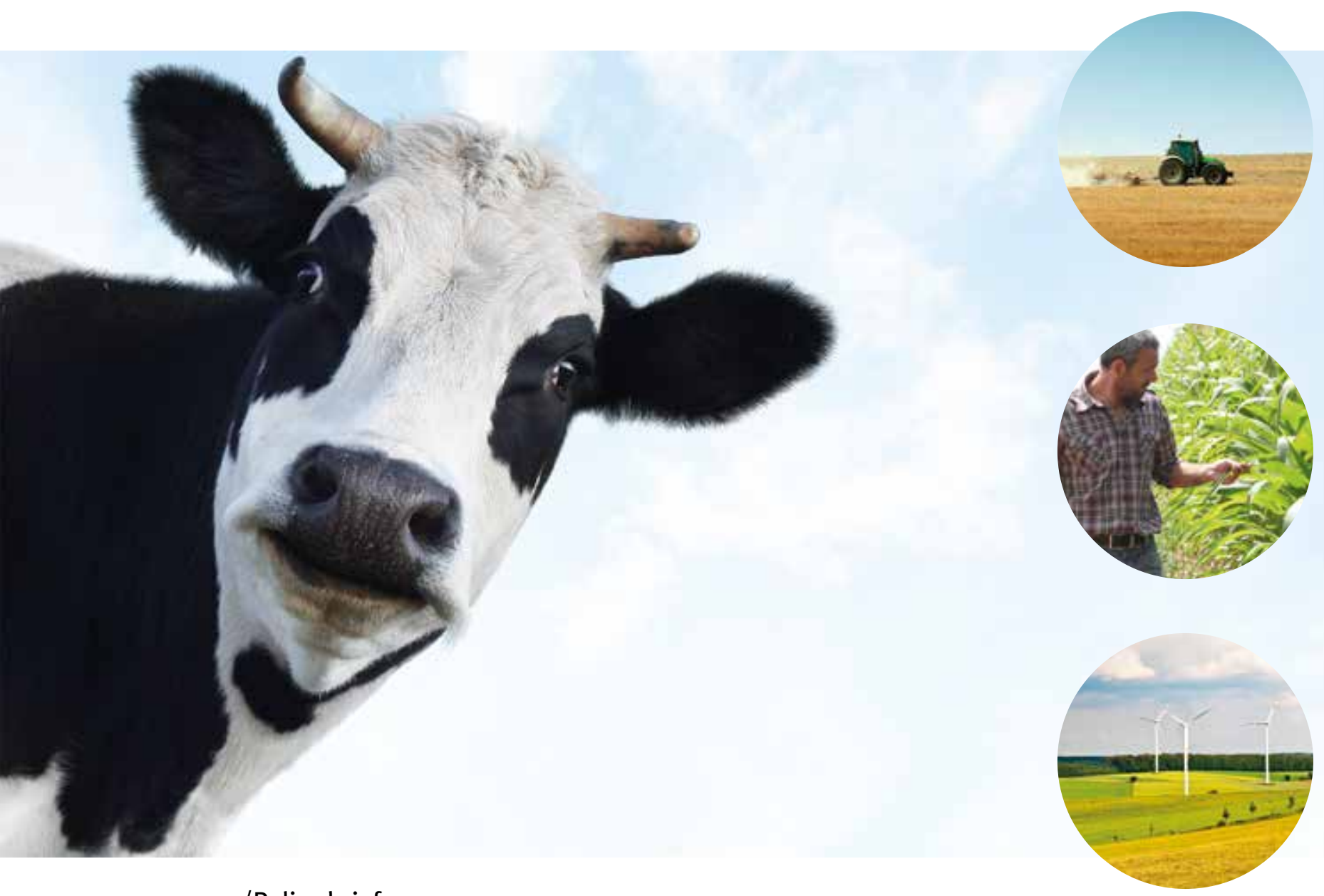

/Policy brief 


\section{Paths to a sustainable agricultural system}

Pathways to a Nordic agricultural and food system with

reduced emissions of greenhouse gases and air pollutants

Kajsa Pira, Miriam Márkus-Johansson, Bente Hessellund Andersen, Stein Brubaek, Tapani Veistola.

Edited by Stefan Larsson

ISBN 978-92-893-4552-1 (PRINT)

ISBN 978-92-893-4553-8 (PDF)

http://dx.doi.org/10.6027/ANP2016-727

ANP 2016:727

(C) Nordic Council of Ministers 2016

Layout: Gitte Wejnold

Cover photo: Shutterstock, SignElements.com

Photo: SignElements.com

Print: Rosendahls-Schultz Grafisk

Copies: 350

Typeface: Meta LF

Paper: Munken Polar

Printed in Denmark

This publication has been published with financial support by the Nordic Council of Ministers. However, the contents of this publication do not necessarily reflect the views, policies or recommendations of the Nordic Council of Ministers.

www.norden.org/nordpub

\section{Nordic co-operation}

Nordic co-operation is one of the world's most extensive forms of regional collaboration, involving Denmark, Finland, Iceland, Norway, Sweden, and the Faroe Islands, Greenland, and Åland.

Nordic co-operation has firm traditions in politics, the economy, and culture. It plays an important role in European and international collaboration, and aims at creating a strong Nordic community in a strong Europe.

Nordic co-operation seeks to safeguard Nordic and regional interests and principles in the global community. Common Nordic values help the region solidify its position as one of the world's most innovative and competitive.

\section{Nordic Council of Ministers}

Ved Stranden 18

DK-1061 Copenhagen $\mathrm{K}$

Phone (+45) 33960200

www.norden.org 


\section{Paths to a sustainable agricultural system}

Pathways to a Nordic agricultural and food system with

reduced emissions of greenhouse gases and air pollutants

Kajsa Pira, Miriam Márkus-Johansson, Bente Hessellund Andersen,

Stein Brubaek, Tapani Veistola.

Edited by Stefan Larsson 


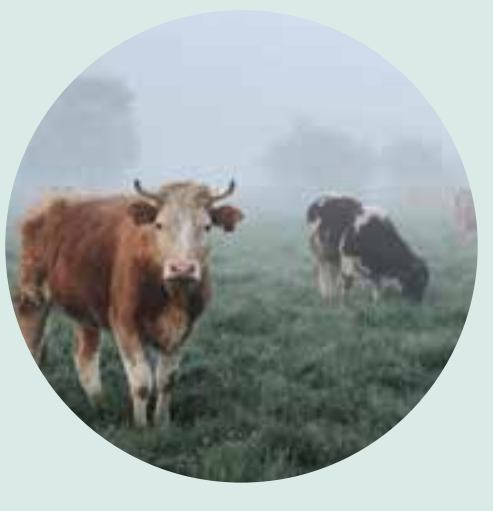




\section{Contents}

$\begin{array}{ll}\text { Key messages } & 8\end{array}$

$\begin{array}{lr}\text { Recommendations } & 10\end{array}$

What is the situation for Nordic agriculture and the associated Greenhouse gas and ammonia emissions?

Understanding the context

Conflicts of interests

What do we want to achieve and how?

Policy implications and recommendations 


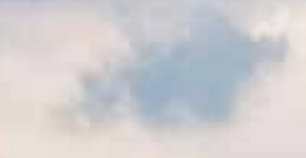

西
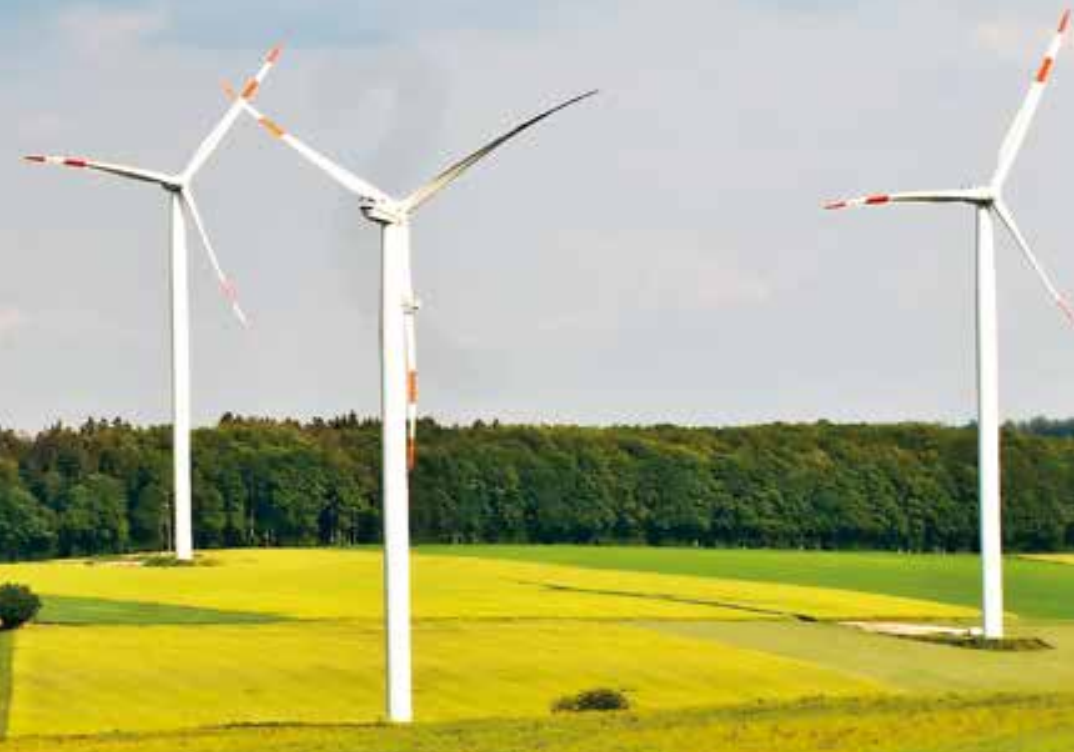

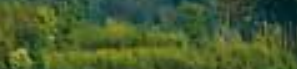

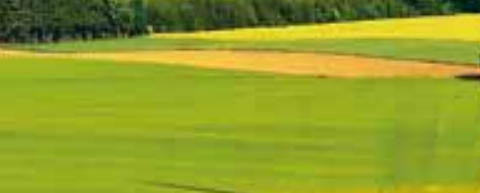

\section{ए}
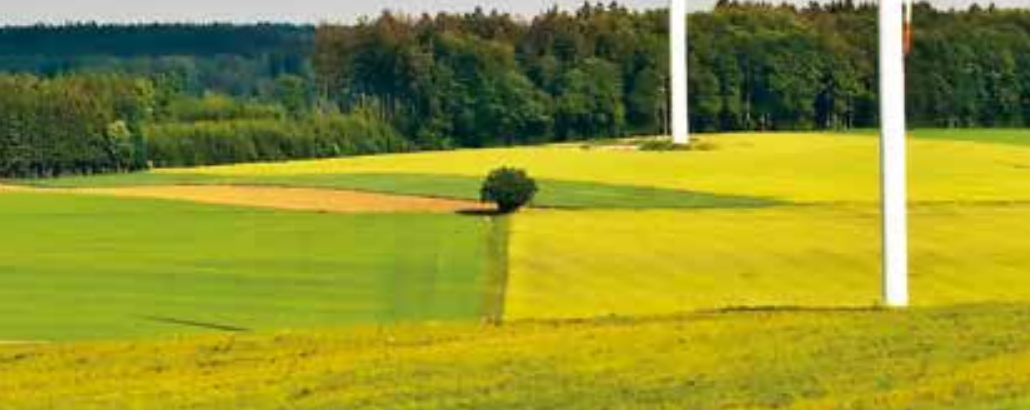

F-

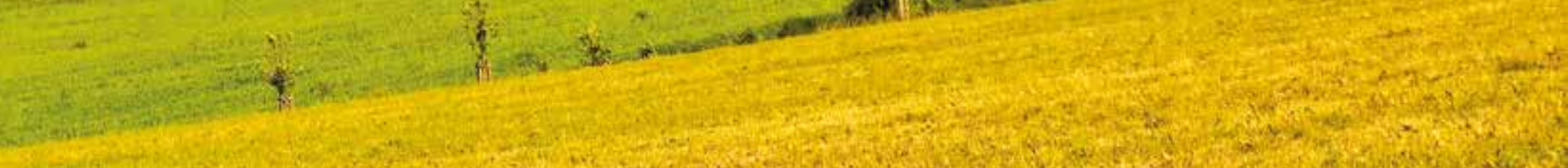

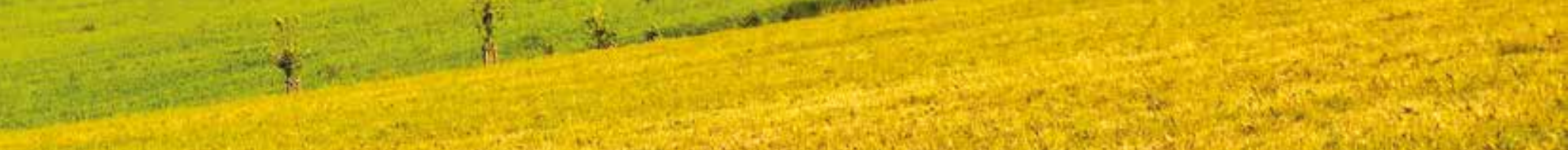

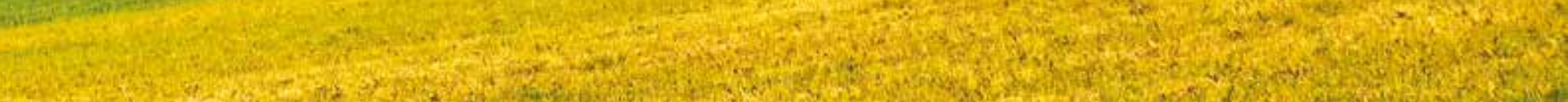

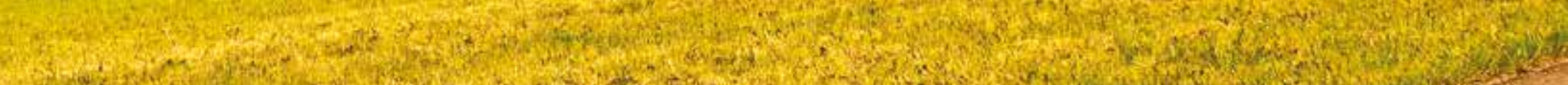

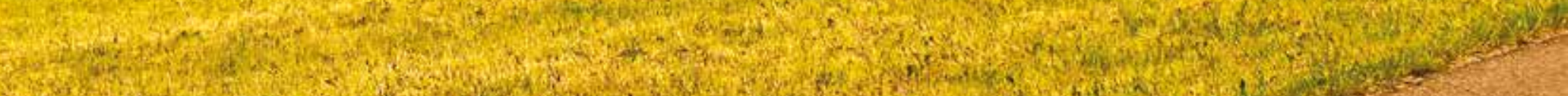

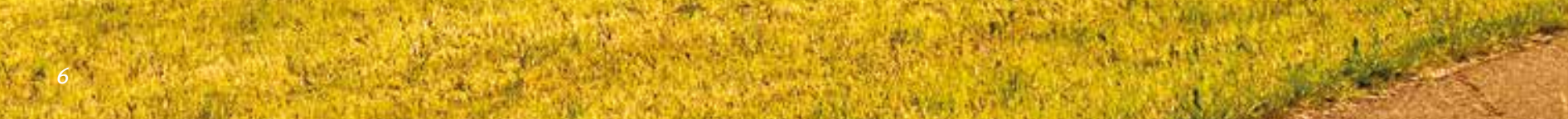
She

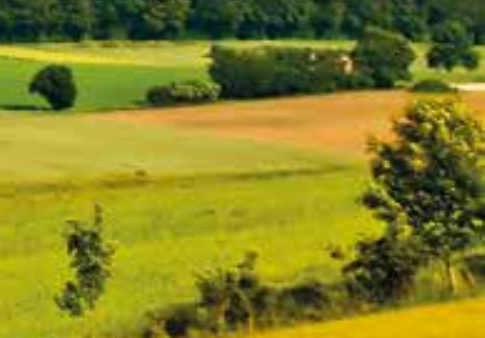


This policy brief constitutes one of the main outputs from the project "Pathways to a Nordic food system that contributes to reduced emissions of greenhouse gases and air pollutants". In co-operation with NOAH in Denmark, Suomen luonnonsuojeluliitto in Finland and Norsk Bonde- og Småbrukarlag in Norway, AirClim in Sweden, has analysed agricultural emissions, regulatory frameworks, food production systems, consumption trends, policies for the agricultural sector and the overall environmental impact in terms of air pollutants and greenhouse gas emissions from agriculture. The analysis also covers conflicts of interest that are counterproductive to an agricultural food production system with lower emissions of greenhouse gases and ammonia.
The project has developed a first inventory of organisational, financial and technical measures to bring down air pollution and greenhouse gas emissions overall within the agricultural sector but also on farm level. This policy brief complements the Nordic baseline reports that was published in August 2015 (http://dx.doi. org/10.6027/TN2015-570). The project is financed by the Nordic Council of Ministers' Climate and Air Pollution Group.

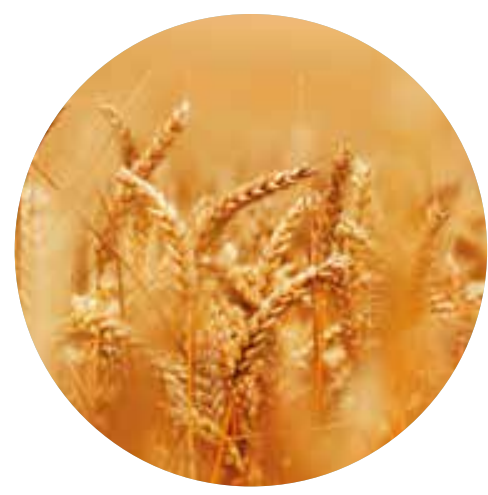




\section{Key Messages}

- Although the Nordic region, to a large extent, is culturally, social and economically homogenous, agricultural structures, topographic and climate conditions, land use and production figures differ significantly between the countries.

- In Norway, Sweden and Finland, a relatively small proportion (3-8\%) of the total land territory is used for agricultural production, while in Denmark more than half of the territory is designated for agricultural production.

- In terms of total emissions of greenhouse gases in each country, the share of methane and nitrous oxide from agriculture in the Nordic countries is 8 and $9 \%$ respectively in Norway and Finland, whereas it is as high as $13 \%$ in Sweden and 19\% in Denmark. If greenhouse gas emissions from land use and energy consumption related to agriculture are added, the share increases significantly and is as high as $27 \%$ in Denmark.

\section{Need for a paradigm shift}

- Differences between the countries makes it difficult to come up with common solutions to farming systems with significantly lower emissions and less impact on climate change but practicies that work in one country may work in another if the knowledge is there.

- We find that such knowledge is currently lacking across the Nordic countries and that the "Nordic public" are dependent on information that the big farmers' and foresters' organisations deliver.

- $\quad$ There are several conflicts of interests counterproductive of the objective to reduce emissions from agriculture that needs to be adressed. These include animal welfare, biodiversity and cultural landscape, farmers' income and land use.

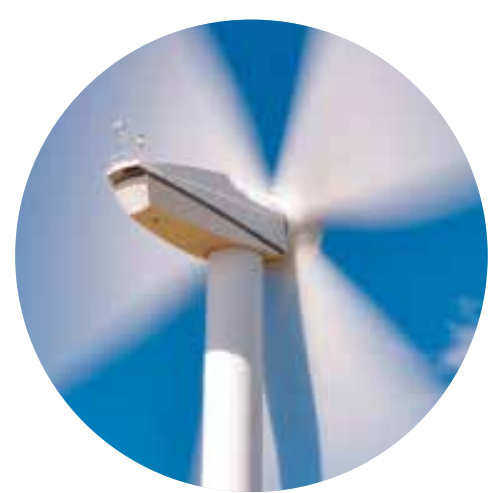


- The agricultural sector and mainly livestock manure accounts for as much as $96 \%$ of the total emissions of ammonia in Denmark and approximately $90 \%$ on average in the Nordic countries. These levels are unlikely to drop significantly unless the right measures and policies being put into place.

- There is a need for a paradigm shift in how we perceive agricultural production, food systems and consumption, the import/export balance, consumption patterns, and how we perceive efficiency in the farming sector and take into account environmental and climate impact factors.

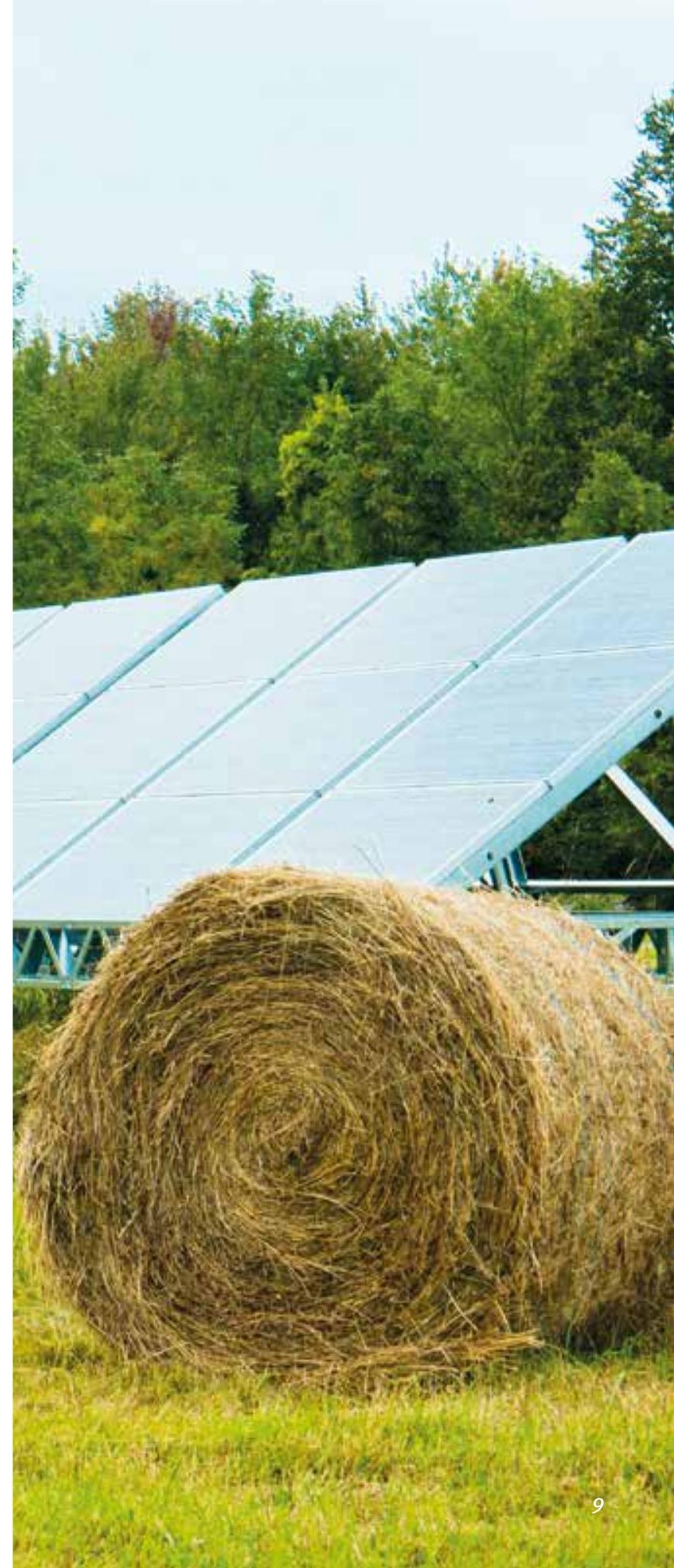




\section{Recommendations}

Nordic action is needed around a vision and pathways that will generate a paradigm shift on many levels and involving many stakeholders and policy areas. One such possible pathway involves increased reliance on agroecology. To make small adjustments in one end will not improve the overall system and may even be counterproductive. Our recommendations for societal and on-the-farm actions are:

- Start working towards an integrated food and agricultural policy, which sufficiently take into account the various issues and conflicts of interests in a holistic way. This policy should also take into account global concerns regarding poverty and unequal access to food.

- Take political action and launch an information campaign to change consumption behaviour, highlighting all potential benefits, e.g. environmental, health and global equality.
- Use targeted measures to raise public awareness of how they can contribute to more sustainable agricultural and food systems and what the results would be on a societal and personal level.

- Promote sustainable farming as a profession, especially among younger generations and extend and further develop the incentive schemes that are already in place. A generation shift is unavoidable as average age of today's farmer is 50 .

- Increase the knowledge about and use of agroecological farming methods that aim to maintain or increase the soil organic matter and limit the use of organic soils for farming, to help bring down carbon emissions from soils.

- Carry out further research to define ways to particularly increase energy efficiency in agricultural and food systems, also at farm level. 
- Put in place adequate regulatory framework and other measures for improved manure management to achieve reduction in greenhouse gas and other emissions. Small-scale farmers may have to receive some assistance (financial and technical) in taking these measures.

- Take measures to reduce the gap between the Nordic countries regarding the usage of technical measures for emission reductions and set up a platform to share experiences.

- More research is needed regarding conflicts of interest to be able to find the right balance between the interests. This balance should be based on various parameters, e.g. the total emission savings of each measure, the cultural and social context, and ethical values.

- It is difficult to consistently apply the polluter pays principle in the agricultural sector but as the main emitter of ammonia and an important source of greenhouse gas emissions, politicians and financial experts need to find ways to internalise the environmental costs.

- Policy makers also need to introduce incentives to promote greenhouse gas reduction measures at farm level. Many of the farms are of smaller size and the individual farmer cannot be expected to take rather expensive measures to contain emissions.

\section{Promote sustainable farming as a profession}

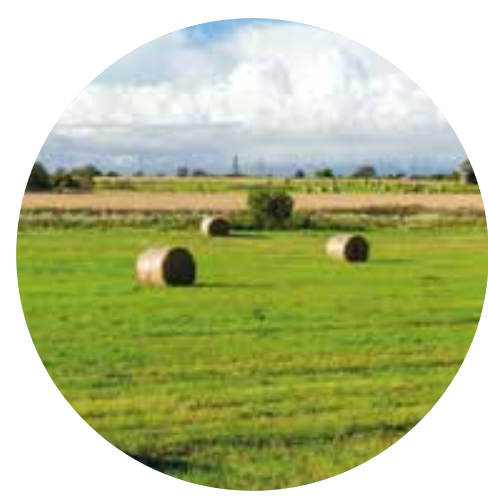




\section{What is the situation for Nordic agriculture and the associated Greenhouse gas and ammonia emissions?}

\author{
Agricultural structures and production \\ The Nordic region is culturally, social and economically \\ very homogenous, but has diverse geological and \\ climatic conditions that make certain types of \\ agricultural production more vulnerable than others. One \\ common factor is that a relatively small proportion of the \\ total land territory is used for agricultural production; \\ between 3 and $8 \%$, except for Denmark, which has \\ more than half of its territory designated for agricultural \\ production.
}

There is a general reduction in the number of dairy herds but an increase in yield per milk cow. The number of farms with cattle has also decreased greatly in the Nordic countries, leading to increased demand for imported meat in some cases. Employment in the agricultural sector is very low - estimated at around $2-3 \%$ of the total workforce, with an average age above 50. In terms of production of grain, meat and other agricultural products, there are some variations between the countries. One general trend is a decline in the production of beef in favour of poultry and pork.

\section{Greenhouse gas and ammonia emissions}

In terms of total emissions of greenhouse gases in each country, the share of methane and nitrous oxide from agriculture in the Nordic countries is 8 and $9 \%$ respectively in Norway and Finland, whereas it is as high as $13 \%$ in Sweden and $19 \%$ in Denmark. If greenhouse gas emissions from land use and energy consumption related to agriculture are added, the share increases significantly and is as high as $27 \%$ in Denmark. Further emissions are connected to imported goods used in agriculture, such as feed and fertilisers.
The share of nitrous oxide emissions from agriculture are highest in Denmark, at 90\%, and lowest in Finland (see Figure 1). All of the countries, except Norway, have seen a reduction in nitrous oxide emissions during the past two decades, which is partly due to decreased use of nitrogen fertiliser.

Methane emissions in the Nordic countries, on the other hand, have remained stable over the past twenty years (see Figure 2).

Ammonia emissions from the agricultural sector are significant (see Figure 3), accounting for approximately $90 \%$ of total ammonia in the Nordic countries. Livestock manure is the main source of ammonia emissions in the Nordic countries, ranging between 80 and $90 \%$, and these levels are unlikely to drop significantly without the right measures and policies in place.

\section{Regulatory framework and support systems}

In terms of regulatory framework and control mechanisms, all the Nordic countries have rules on the spreading, storing and use of manure, with the Danish regulations being the most rigorous.

Some incentive and support systems have been put into place that can either work in favour of or constitute barriers to a paradigm shift in Nordic agricultural and food systems. For instance, the present support systems for agriculture have mainly favoured more intensive and large-scale farming. Another fact of significance is that growth in production has historically been central to agricultural policy, while other interests were seen as less important. 


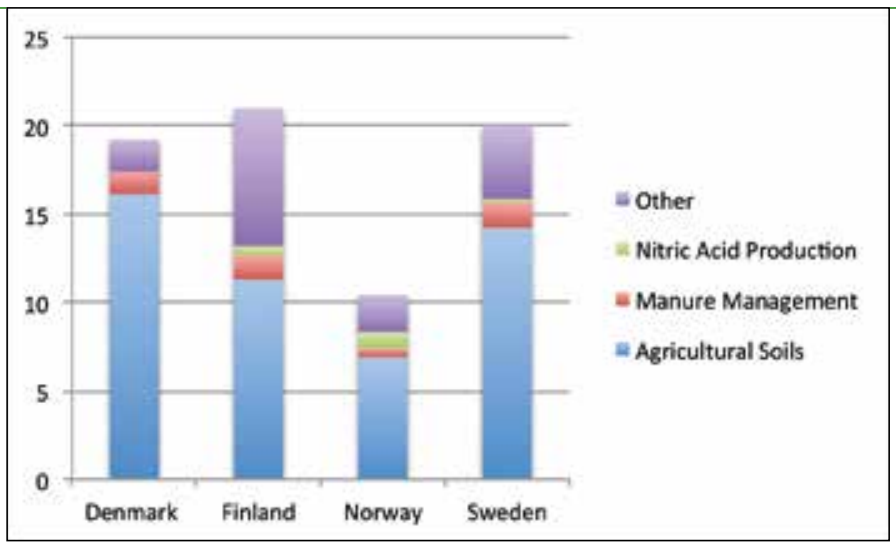

Figure 1: Nitrous oxide emissions (thousand tonnes) in 2012 (EEA tech report No 09/2014).

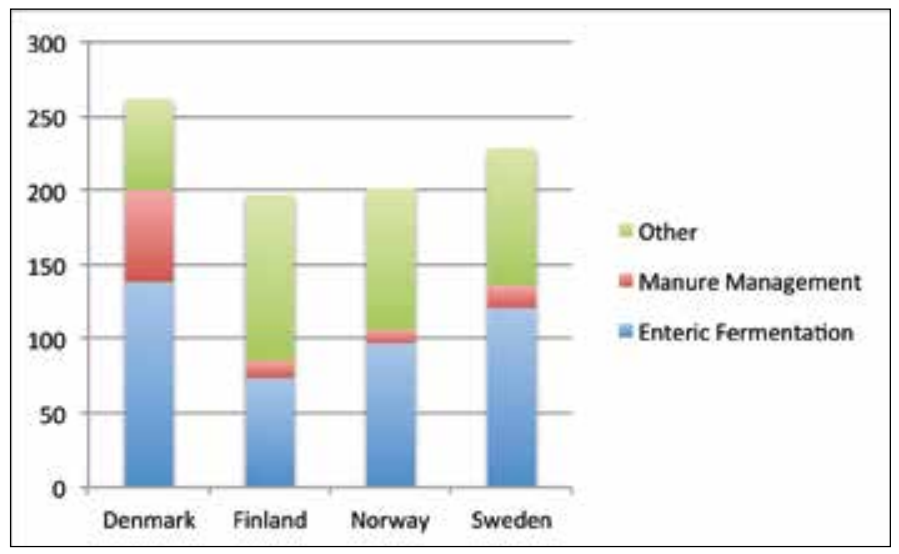

Figure 2: Methane emissions (thousand tonnes) in 2012 (EEA tech report No 09/2014).

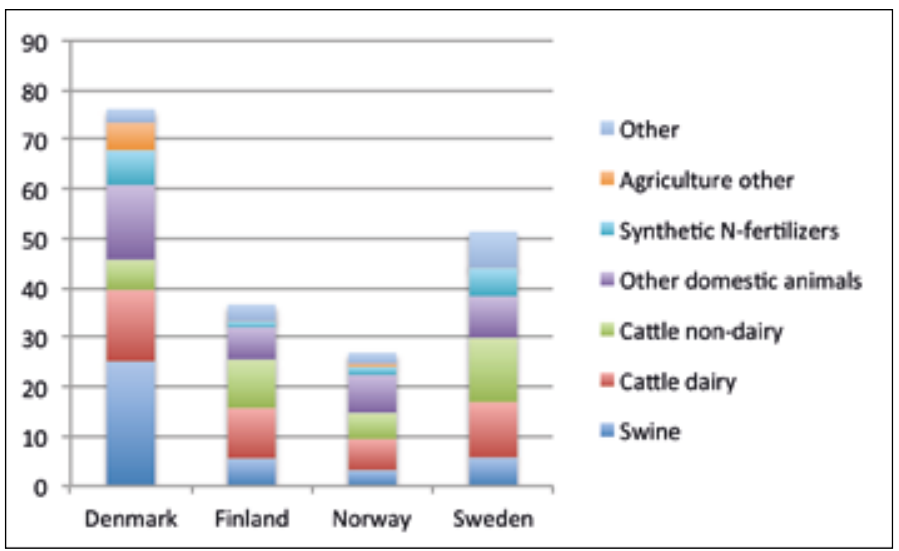

Figure 3: Ammonia emissions (thousand tonnes) in 2012 (EEA tech report No 12/2014). 


\section{Integrated system analysis - relations between different factors}

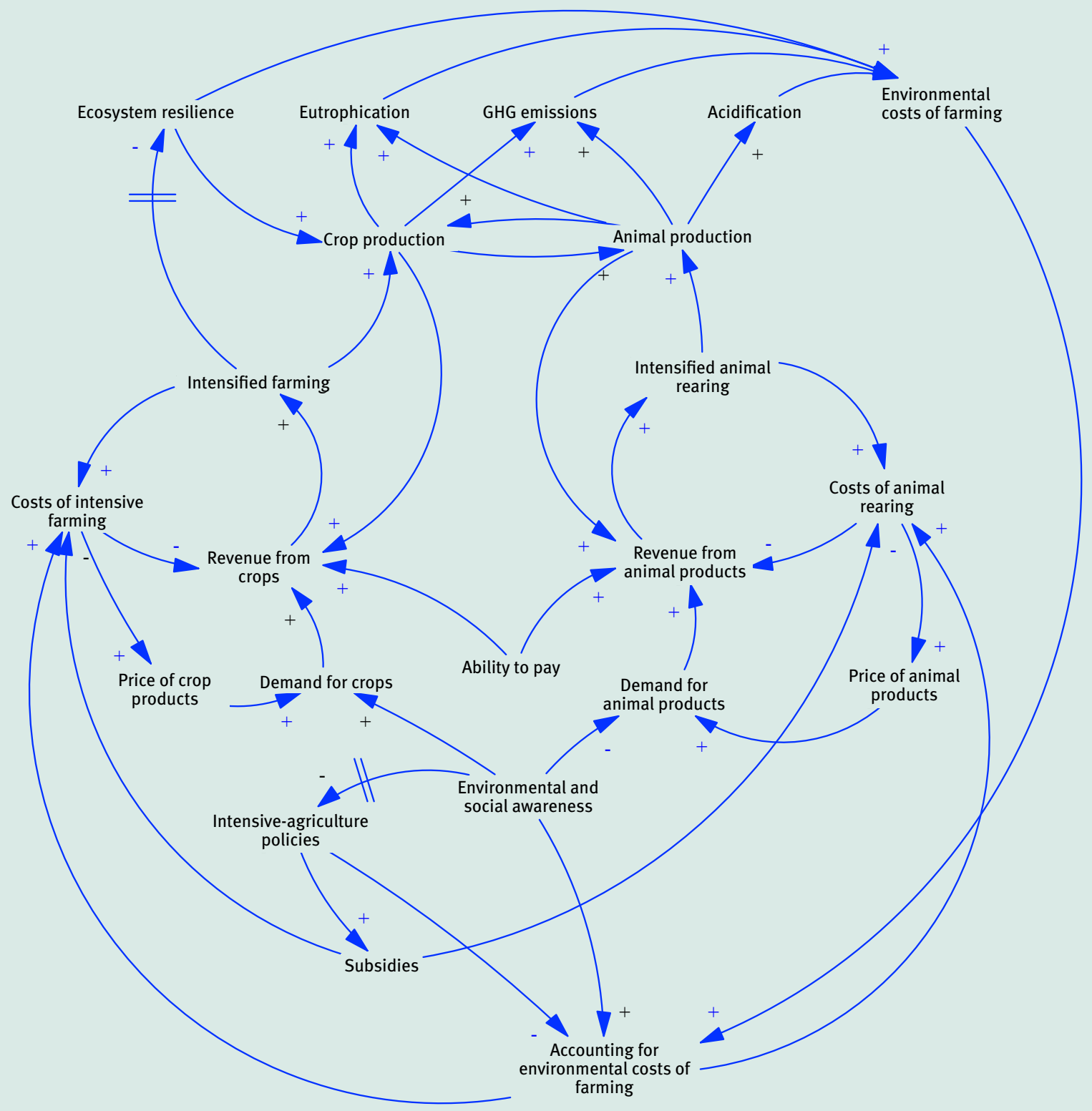

Figure 4: A holistic picture of the drivers behind emissions from agriculture. 


\section{Understanding the context}

Agricultural and food systems must be seen in a larger context taking a holistic perspective. Two issues that the project has focused on in this respect are conflicts of interests and integrated system analysis. The latter methodology helps detect and understand the conflicts of interests.

There are many links and dependencies between the various elements and factors that affect agricultural systems and food systems. The Causal Loop Diagrams that were modelled and discussed in two workshops in 2014 and presented in the Nordic baseline report of September 2015 can be combined to one diagram (see Figure 4, above) aiming to shortly explain the behaviour of the entire system. This diagram focuses on the following key components:

1) Less intensive farming - Smaller farms have lower animal densities and are often related to local consumers with smaller consumption of animal products. It is also likely that a reduced dependency on external inputs and the ability to use local resource flows will lead to lower emissions.

2) Profitability - This is a crucial factor in the choice of production systems and in turn related to costs for inputs, access to market and imports, degree of free trade and competition, consumer demand for products, agricultural policy and design of support system for agriculture.
3) Consumer choices and preferences - These depends partly on their ability and willingness to pay, based on factors like consumer income, food prices, cultural context, environmental and health awareness and consumption preferences. In most countries, where consumers ability to pay increases, there is also an increase in the consumption of relatively more expensive but also more emissions-intensive products such as meat and cheese. Whether this still applies at the level of prosperity that the Nordic countries have achieved is unclear.

4) Support/subsidy systems - The systems for agriculture that are currently present have mainly favoured intensive and large-scale farming. This is partly due to the fact that large scale and intensive farmers often have been better represented by the sector's own interest organisations. An increased production historically has been central to agricultural policy and other interests have been subordinated. There is a need to revise the support system in order to promote a more environmentally and climate friendly agriculture.

5) Externalisation of environmental costs - Agriculture today does not pay for the external environmental and health costs that the emissions from agriculture causes. This can be seen as an indirect subsidy to agriculture with high emissions. One reason for the absence of environmental taxes in agriculture is that emissions are often diffuse and difficult to measure. The competition on a global market (and especially in the EU) is another reason that few countries dare to go further in terms of environmental taxes and regulation. 


\section{6) Public environmental and social awareness -}

Theoretically, in a transparent and working democracy, an increased public awareness would lead to both the internalisation of the environmental costs associated with intensive farming, a revision of the subsidies system promoting low agricultural product prices, and a reevaluation of consumer choices regarding the consumption of crop and animal products. However, in practice more measures and awareness raising is necessary to achieve this internalisation of environmental costs and to reach a paradigm shift in agricultural production and consumption of agricultural products.
7) Global and cultural considerations - The integrated system analysis must also take into account issues such as the international trade regime, global famine, unequal access to food, and cultural landscape policies.

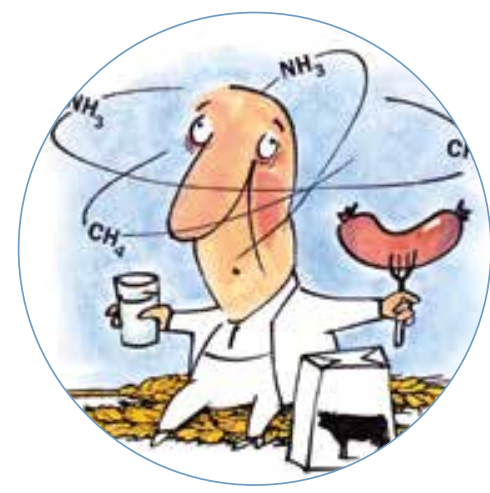




\section{Conflicts of interests}

There are several conflicts of interests counterproductive to the objective of reducing emissions from agriculture. We have addressed a few of these conflicts.

\section{Animal welfare}

- The area for manure littering is usually greater in free-range (indoor) systems and the manure is in a solid form, which is difficult to handle. However, the stables are good for animal welfare and the solid manure is considered very beneficial for the soil structure.

- Slotted floors are an efficient way to collect animal manure, but can cause injuries to animals' feet.

- A short lifecycle for livestock will lead to lower greenhouse gas emissions per kilogram of product, however breeding for fast growth may cause health problems for animals.

- Keeping animals indoors all year round makes it possible to use scrubbers and filters to clean the air from emissions and a better possibility to collect all the manure, but at a cost for animals.

\section{Biodiversity and cultural landscape}

- Grazing animals, especially on permanent grasslands, are of great importance for biodiversity and increase the potential for soil carbon sequestration. Open pastures also have cultural and aesthetic values.
- It is debated whether these systems are more or less efficient when it comes to greenhouse gas emissions per kilogram of product.

- Interventions to decrease consumption of animal products could lead to less areas being grazed, if not combined with other interventions.

\section{Farmers' income}

Technical systems that lead to lower emissions require investments in machinery and housing. Many farmers in the Nordic countries are already struggling to survive economically. New minimum standards might be the straw that breaks the camel's back and lead to the decision to close a farm. In highly productive areas this often leads to the farm being bought by the neighbouring farm, which contributes to the trend towards ever-larger units. In less productive areas, it usually implies that agricultural land will be converted into forest.

\section{Land use}

It is debated whether low-input ecological farming methods are viable farming systems, as more land is used to produce a unit of food (e.g. a kilo of grain or meat, or a litre of milk) compared with intensive farming systems that have high inputs of fertiliser, pesticides and energy. On the other hand, the low-input systems may preserve biodiversity, water and landscapes, and take more care of animals' welfare. Hence, ecological farming systems require diets based on relatively more vegetable and less animal products. 


\section{Challenges of global agriculture}

The main purpose of agriculture is to produce enough healthy food for the world's population. In a situation where the number of people on Earth who are starving has in the last 30 years remained stable between 800 million and 1 billion in spite of the so-called green revolution, it is necessary to take a close look at how production takes place, where it takes place, and how food is distributed.

The need for sustainable food production becomes even more apparent when one assumes that for every degree that the temperature rises around the globe, crop production decreases by $10 \%$. Set against the backdrop of the international challenges, the world has to produce enough healthy food in a sustainable way and to allocate the resources fairly.

A Nordic climate project for agriculture cannot therefore unilaterally propose technical measures to camouflage and limit emissions due to agriculture, or accept production methods in Scandinavia (based on large amounts of imported fodder) without taking into account the greatest challenges facing the Earth and humanity.
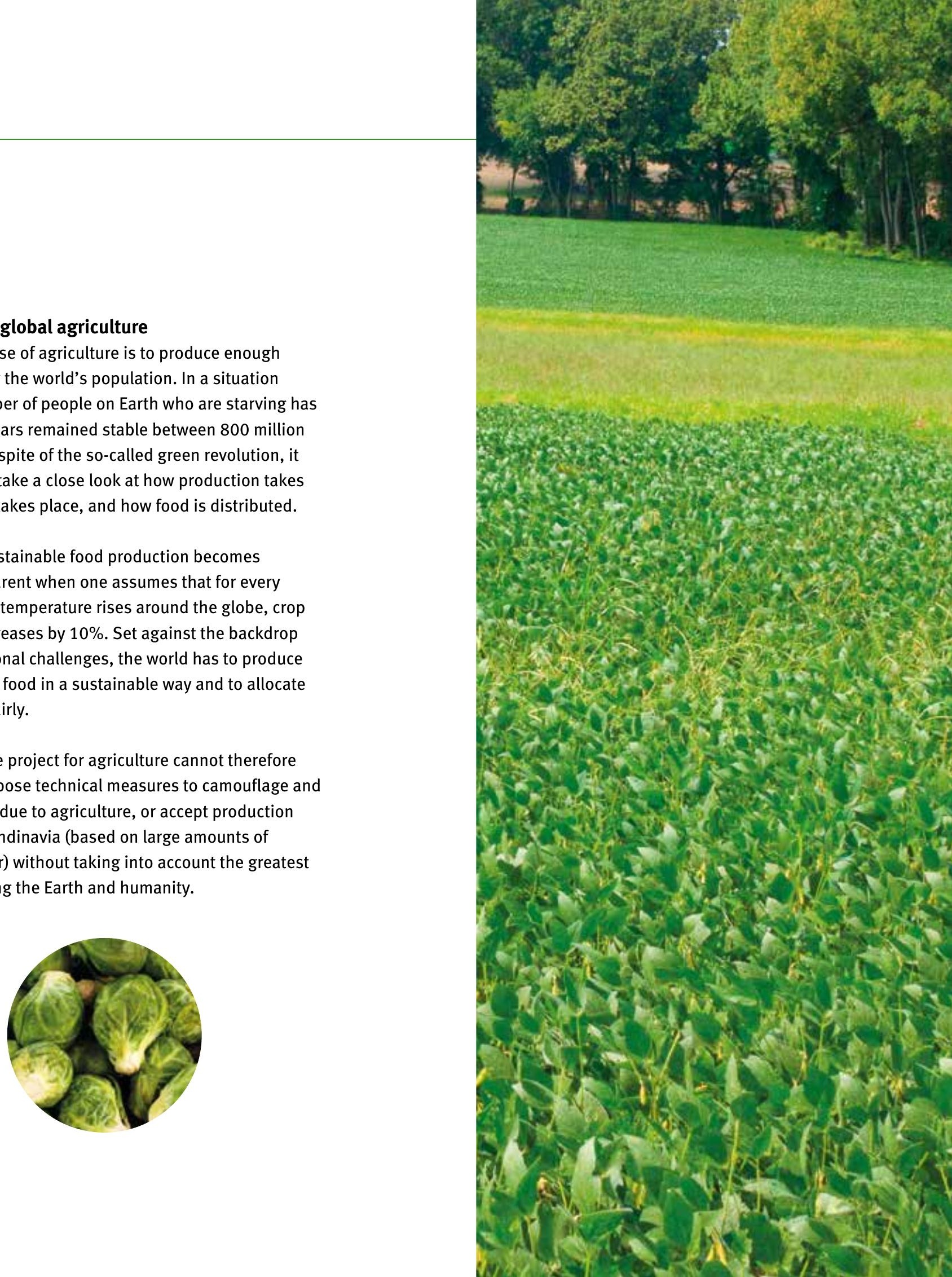


\section{What do we want to achieve and how?}

\section{Technical, financial and organisational measures}

In order to see to what degree a variety of complementary measures is used to restrict emissions from the agricultural sector, we have made an inventory of measures, divided into various categories, i.e. manure and fertiliser management, energy efficiency, feeding, land use, production of energy from the agricultural sector, and other measures. The measures most frequently used on a regular basis are in the first category of measures, i.e. manure handling and fertilisation. These include:

1) Decreasing the time over which emissions can take place.

2) Covering of slurry tanks.

3) Covering and/or turning over of solid manure heaps.

4) Optimising fertilization.

5) Decreasing the surface area where emissions can take place.

6) Increasing the use of green manure (legumes) in fields.

The category of measures most scarcely used was energy efficiency measures, e.g. using energy-efficient ventilation systems, reducing energy use from milking, and replacing diesel with renewable fuels. Energy production from agricultural input (biomass, manure, straw) is also seldom deployed; however this practice is also controversial in relation to possible displacement of food production and/or carbon depletion in soils. Regarding measures that relate to food and consumption that will bring down carbon emissions, including decreasing the number of animals, reducing meat, milk and egg production - the most frequently used measure was linked to "reducing food waste".

These measures deserve a closer examination as they behold lots of potentials for both mitigating the climate and air emission impact of agricultural and food systems. In the next phase (se below) of the project we will try to assess these measures individually and in combination in a performance matrix.

\section{Towards new pathways - building a Nordic scenario}

During the next year of the project, the project partners in dialogue with farming organisations, agricultural ministries, EU and international organisations, will build a scenario for a sustainable Nordic agriculture with significantly reduced greenhouse gas and ammonia emissions. In this scenario it will be possible to produce healthy and sustainable food whilst minimising the environmental impact, increase the sense of purpose, pride and responsibility for farmers and increase the focus on maintenance of healthy biological processes in agricultural practices - in contrast to pure economic conditions.

The scenario work will consider a number of predefined parameters. For instance the scenario and paths proposed will have to be capable of significantly decreasing GHG emissions and possibly involving carbon sinks in farming systems as well as decreasing ammonia emissions. Furthermore, achieving sustainable food systems do not imply that we move food production abroad since that only leads to exporting emissions. 
The results should also contribute to over-all improved environmental protection including reduced use of pesticides and other chemicals as well as to maintain or improve biodiversity. Any environmental gains should also be without a sacrifice in animal welfare. Also one has to work towards securing farmer's income and reducing indebtedness as well as to create new jobs in the agricultural sector.

Some of the underlying assumptions on which the scenario work will build include:
1) Sense of need for firm action to address environmental/ climate effects of the agricultural sector.

2) People in general are willing to change food habits if they are well-informed and engaged in dialogue and change is not too costly.

3) Farmers are willing to change farming practices if their income and working conditions are maintained or improved.

4) The Nordic populations share, to a large extent, the same views and is an ideal region to develop a joint scenario and platform for sustainable agricultural and food systems.

\section{It will be possible to produce healthy and sustainable food whilst minimising the environmental impact}
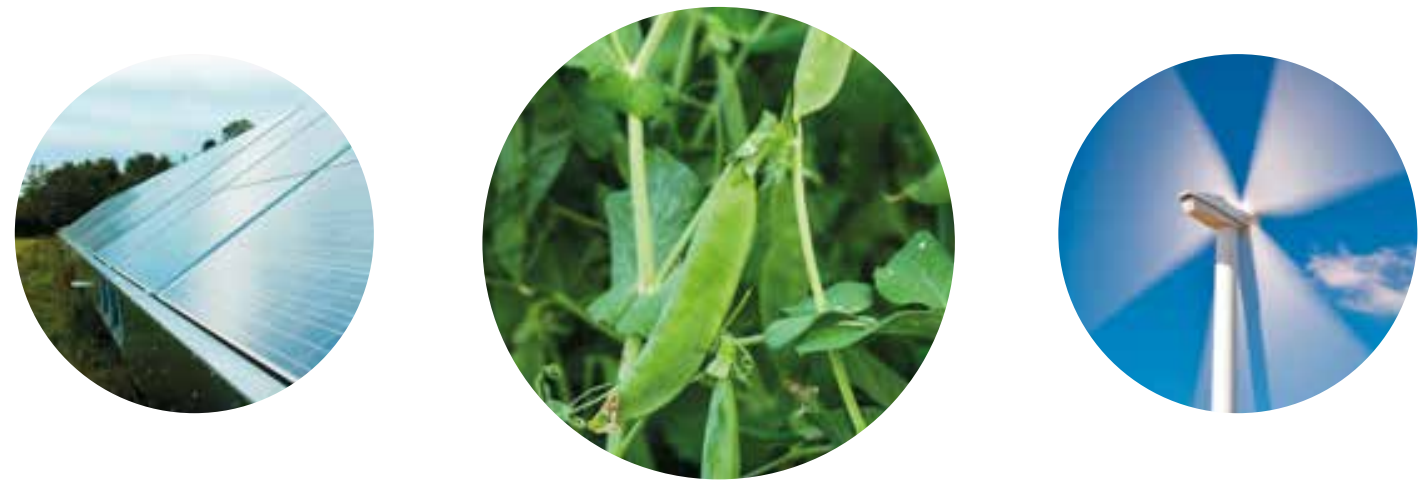


\section{Policy implications and recommendations}

What does this mean for the development of Nordic agricultural and food system policy? This project has provided policy makers, the participants of the steering group, other participants and stakeholders with a better insight into the strengths and weaknesses of the Nordic agricultural and food systems, especially regarding their contribution to ammonia and greenhouse gas emissions and the paths to change the situation.
This information and the forthcoming scenario results will enable policy makers to unite around a vision for a sustainable Nordic agricultural and food system policy, action plan and road map to implement measures at all levels. A firm Nordic vision can also be a tool for Nordic negotiators for advocating for further emission reductions at Nordic, EU and international level, which also involves negotiations in relevant MEAs (multilateral environmental agreements).

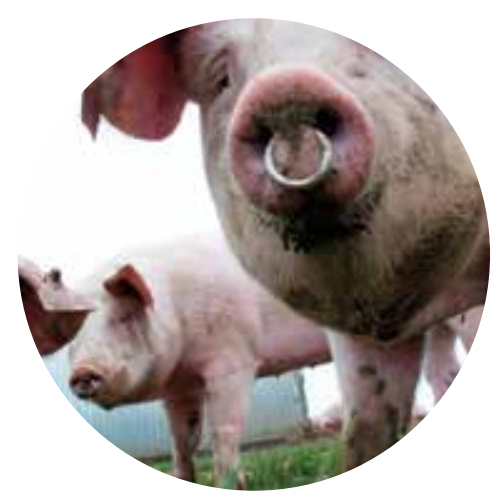




\section{norden}

Nordic Council of Ministers

Ved Stranden 18

DK-1061 Copenhagen K

www.norden.org

This policy brief constitutes one of the main outputs from the project "Pathways to a Nordic food system that contributes to reduced emissions of greenhouse gases and air pollutants". In cooperation with NOAH ( Denmark), Suomen luonnonsuojeluliitto (Finland) and Norsk Bonde- og Småbrukarlag (Norway), AirClim (Sweden) has analysed agricultural emissions, regulatory frameworks, food production systems, consumption trends, policies for the agricultural sector and the overall environmental impact in terms of air pollutants and greenhouse gas emissions from agriculture. The analysis also covers conflicts of interest that are counterproductive to an agricultural food production system with lower emissions of greenhouse gases and ammonia. The project is financed by the Nordic Council of Ministers' Climate and Air Pollution Group.

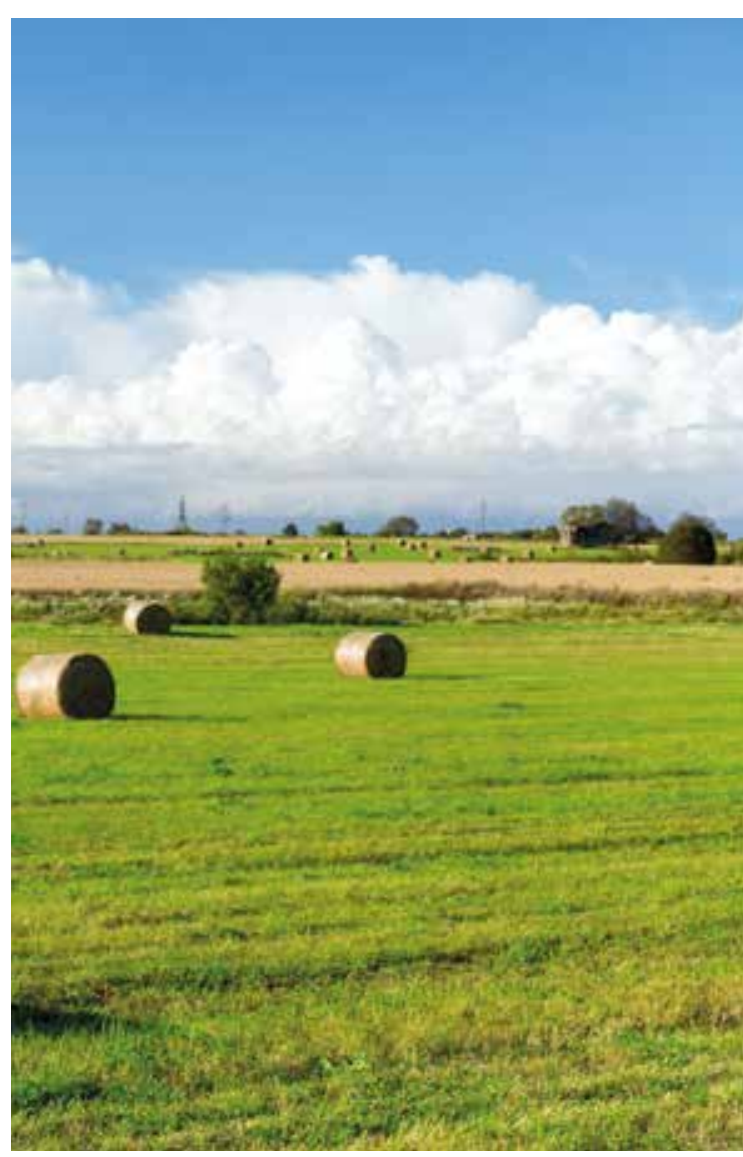

